\title{
Etnogénesis en las fronteras entre Brasil, Surinam y Gua- yana Francesa, siglos XVII-XX: más aproximaciones ${ }^{1}$
}

\author{
Ethnogenesis in the borders of Brazil, Surinam, and French Guiana \\ in the seventeeth and eighteenth centuries: a close view
}

\author{
Flávio Gomes*
}

RESUMEN

Neste artigo voltamos a analizar os procesos históricos de transformações étnicas e de etnogenesis nas fronteiras amazónicas, especialmente entre Brasil, Suriname e Guiana Francesa. Com registros da documentação colonial e pós-colonial, do século XVII ao XX é possível abordar os movimentos migratórios de diferentes grupos étnicos - em parte indígenas, africanos, seus descendentes e outros setores coloniais - nas áreas de fronteiras, considerando as conexões culturais. Surgem diferentes narrativas e imagens sobre a formação destes grupos e suas funções nas áreas de fronteiras e disputas territoriais transnacionais.

PALABRAS ClAVE: Fronteiras transnacionais. Guiana Francesa. Suriname.

\section{ABSTRACT}

In this article analyzes historical processes involving ethnic transformations in the Amazon borders, especially those of Brazil, Suriname, and French Guiana. Through records of colonial and post-colonial sources produced between the 17th and 20th centuries, it focus on the colonial population movement of diverse ethnic groups - such as Indians, Africans, their descendants, among others - in the boundary areas, considering the cultural connections. This perspective reveals how different narratives and images the formation of these groups emerges, as well as their functions in boundary areas, besides international disputes related to territories.

KEYWORDS: Transnational borders. French Guiana. Suriname.

Tal vez aún más que en el siglo XVIII, las fronteras - o lo que llamamos como tal - continúan siendo desconocidas. Para el universo historiográfico, hubo prácticamente un destierro. En las historiografías aún marcadas por la perspectiva de historia nacional, conocemos poco sobre espacios y tiempos en las fronteras, muchas de las cuales son transnacionales. En relación a las áreas coloniales y postcoloniales entre los siglos XVI y XIX, muchos estudios se limitaron a las interpretaciones sobre las lógicas de los imperios y las estrategias - no siempre convergentes - de dominio y poder. Existen, todavía encubiertos, diversos y complejos procesos de etnogénesis, desde las cosmologías indígenas a las expectativas de los contactos y las primeras generaciones de

\footnotetext{
* Una primera versión más abreviada de este texto fue publicada en GOMES, Flávio dos Santos. Los cimarrones y las mezclas étnicas en las fronteras de las Guayanas. Siglos XVII-XX. Procesos de História, Revista Semestral de Historia y Ciencias Sociales, Universidad de Los Andes, Venezuela, v. 16, p. 24-39, 2009.

2 Universidade Federal do Rio de J aneiro - UFRJ, Instituto de História, Laboratório de Antropologia e História (LAH).
} 
colonos y trabajadores. Sabemos un poco acerca de las lenguas y lenguajes, pero muy poco acerca de la cultura material.

Existen fases históricas, arqueológicas y antropológicas que continúan ocultas en análisis que acentúan las dinámicas coloniales de ocupación y economía cristalizadas. ¿Cómo interactuaron las innumerables micro-sociedades con diversos sectores coloniales, especialmente los mundos de los trabajadores en las áreas de fronteras? ¿Cómo fueron percibidas las políticas de colonización a partir de lógicas propias, resultando en patrones adaptativos de asentamiento, migración, parentesco y desplazamientos geográficos?

Los movimientos transétnicos en las fronteras - a través de etnogénesis de poblaciones de trabajadores forzosos, indígenas y africanos - pueden ser interesantes puestos de observación. En diferentes partes de la extensa Amazonía -- especialmente donde había reducciones y organización del trabajo obligatorio, además de vínculos económicos - hay registros sobre el aumento de fugas y el establecimiento de fugitivos en nuevas comunidades, en un proceso de etnogénesis aún poco conocido. Considerando la etnología, relatos contemporáneos de misioneros y viajeros y las narrativas de la documentación colonial, sería posible avanzar en la reflexión etnohistórica de los cambios y de los conflictos contextuales - colapso demográfico, esclavización, migración, genocidio etc. - envolviendo diversos pueblos y culturas. En la Amazonía colonial, las poblaciones indígenas gestaron, de forma sistemática, una tradición de migraciones y formación de grupos de fugitivos. Aún considerando la inmensidad de esta región, el escaso poblamiento y la dispersión de aldeas y poblados, los indios nunca permanecieron aislados. Muchos procesos coloniales - que podrían llamarse metacoloniales -- deben ser pensados también a partir de las lógicas de las poblaciones envolventes, sus movimientos, constituciones demográficas, culturales, simbólicas y políticas. Procesos de etnogénesis -- en términos de historia y etnología -- permanecían encubiertos.

\section{Espacios Transnacionales en la Guayana Francesa, Siglos XVII-XVIII}

Los conflictos y las mezclas explican las formaciones de las comunidades de fugitivos en las fronteras coloniales de las Guayanas, áreas de posesiones portuguesas, españolas, francesas, holandesas e inglesa. Baena destacó que las disputas se agravaron el último cuarto del siglo XVII, durante la exploración de las tierras alrededor del río Oiapoque, que pertenecían a Portugal desde 1636. Se sabía que los franceses habían extendido sus exploraciones hasta la desembocadura del río Amazonas. En 1685, las autoridades coloniales portuguesas le reclamaban al gobernador de Cayena que los franceses iban al Cabo Norte a comprar indios cautivos. Tres años más tarde, el Rey de 
Portugal recibió una denuncia diciendo que habían encarcelado y maltratado a los franceses, acusados de mantener el comercio entre Cayena y el río Amazonas (BAENA, 1846).

A las autoridades lusitanas siempre les preocuparon los intercambios mercantiles - en las fronteras - entre los colonos franceses y los grupos indígenas. Además, los comerciantes y los indios ayudaban a los esclavos africanos y criollos ${ }^{*}$ a refugiarse, tanto del lado portugués como del francés. En 1732, las dos Coronas firmaron un tratado internacional, donde acordaban devolver a los fugitivos. Entre tanto, los conflictos territoriales hacían cada vez más difícil el control y la vigilancia de esa área tan extensa. Reinaba la desconfianza mutua con respecto a los dominios y a los territorios coloniales. En un intento por cumplir los acuerdos diplomáticos, las autoridades coloniales intercambiaban fugitivos recíprocamente. Pero las reclamaciones continuaban, a tal punto que una vez, el gobernador de Pará declaró que los colonos franceses y el gobernador de Cayena, le habían enviado cartas con palabras "ásperas" sobre su tardanza en devolver a los fugitivos y recordaba que no siempre los franceses cumplían el Tratado de Utrecht (SALLES, 1971, p. 221-222). ${ }^{3}$ Todavía en 1727, las tropas lusitanas y francesas subieron a la montaña D'Oyon, en la boca del río Oiapoque, para inspeccionar los límites de la frontera, estipulados por el tratado. El problema era más complejo y no se limitaba sólo a las fugas, ya que el territorio era escenario de conflictos coloniales. Lo principal era ocupar los territorios ya que los portugueses, los españoles, los holandeses y los franceses, se cruzaban allí (no sólo para buscar fugitivos) y mantenían relaciones con los indígenas, que apoyaban el cimarronaje. En 1724, un barco de la Guayana Francesa fue encarcelado en Pará, siguiendo una disposición del Consejo de Ultramar. Se descubrió que la intención de sus tripulantes era hacer comercio. Cualquier movimiento generaba recelos y redoblaba la vigilancia. En 1733, las autoridades lusitanas devolvieron 25 esclavos y le exigían reciprocidad a los franceses. Al año siguiente, el Rey Don J uan I le escribía al Capitán General del Estado de Grão-Pará, informándole sobre la restitución de los esclavos venidos de Cayena, que querían refugiarse en tierras lusitanas. En 1739, la Corona Portuguesa determinó castigos para los que ayudaran a los refugiados en las fronteras (BAENA 1846, 39-41; Anais da Biblioteca e Arquivo Público do Pará, 1930, vol. VII, 209; vol. II e IV, 9 y s168).

\footnotetext{
- Nota del Traductor: A diferencia de lo que ocurre en los antiguos territorios españoles de América donde se denomina "criollo" a los descendientes de europeos nacidos en la colonia, en Brasil se denomina "criollo" a los descendientes de los esclavos africanos nacidos en su territorio.

3 Instituto Histórico Geográfico Brasileiro (em adelante IHGB), Conselho Ultramarino, Évora, tomo V, arch. 1.2.24, fl. 149 v. y tomo VII, arch. 1.2.26, fl. 180 v. y Códice Arch. 1, 2, 26, Conselho Ultramarino, Évora, volume VII, fls. 193v y 194.
} 
Las fugas sólo aumentarían. En 1752, el gobernador de Cayena pidió que le devolvieran 19 negros. En 1757 las denuncias constatan la presencia de emisarios franceses que se infiltraban con la excusa de vigilar el movimiento de los fugitivos. En 1760, la venida de Monseñor Galvete a Belén de Pará para recoger esclavos negros estuvo acompañada de quejas. En 1767, dos canoas con oficiales franceses bajaron el río Oiapoque con la intención de buscar fugitivos negros. Aunque la selva fuera inmensa y, por lo tanto, un refugio garantizado, los itinerarios de las fugas eran arriesgados. Saliendo de Cayena en dirección a Pará o viceversa, generalmente los fugitivos optaban por el mar y/ o los ríos que bañaban la región. Hacer frente a la selva impracticable era impensable. Serían presas fáciles del hambre, de los animales feroces, las fiebres y los rastreadores, principalmente de los cazadores franceses. En el lugar llamado Pesqueiro, en Macapá, por ejemplo, una vez se encontraron los cuerpos de tres fugitivos "que murieron, no sé si de hambre o por las fieras, porque los vestigios no dan una buena información sobre el acontecimiento ya que se encontraban muy lejos de valles y ríos, y sólo libres las sierras y las colinas". Por vía fluvial, construyendo canoas y balsas, se aventuraban. De Amapá, en 1765, llegaban informaciones de que algunos habían cruzado el río Matapi en balsas, y que podrían encontrarlas en las praderas del río Uanará-Pecú y en los lagos del Río Arapecú donde también se habían encontrado vestigios ciertos (RIHGB (320) 17-48 y RIHGB (58) 215-223). ${ }^{4}$

Los años pasaban, los conflictos coloniales estaban lejos de acabar y las fugas continuaban. Con ellas, seguían también las reclamaciones coloniales y la formación de mocambos. Llegaban a Pará canoas de Cayena para rescatar a los fugitivos. E igualmente era conocido que negros venidos de la región de Cayena estaban en la región de la punta de Maguari y de Caviana. Pero las rutas no iban en un sólo sentido. A pesar de las quejas continuas de los franceses, se sabía que el movimiento de fuga de Pará en dirección a Cayena también era constante. ${ }^{5}$ En septiembre de 1773 algunas noticias señalaban que un grupo de fugitivos que había salido de Pará ya estaba en Cayena. Según el jesuita Laillet: "hace poco más de dos años llegaron siete negros aquí a Cayena, después de varias luchas y muertes, pero fueron mal recibidos", es decir, castigados y encarcelados (RIHGB, 1893, v.6, p.163-165). ${ }^{6}$

\footnotetext{
4 Archivo Público de Pará (en adelante APEPA), Anales VII, documento 428, pp. 209, Oficio del 16/03/1734; Códice 695 (1752-1757), Oficio del 17/08/1755 y Códice 667 (1756-1778), Oficio del 26/ 05/ 1756; Carta del Gobernador de Pará, Manoel Bernardo de Mello e Castro, enviada al Rey de Portugal, 22/ 08/ 1759 y 08/11/ 1760 y Códice 696 (1759-1761), Oficio del 06/ 04/ 1767.

${ }^{5}$ APEPA, Anales II, documento 9, Oficio del 14.11.1752; Códice 07 (1752), 26/04/ 1763; Códice (1793-1799), 06/02/ 1793; Códice 61 (1765), 11/ 10/1765; Códice 65 (1765), 28/08/1765 y Códice 255 (1789-1790), $04 / 02 / 1789$.

6 APEPA, Códice 671 (1768-1773), 20/ 01/ 1768; Códice 65 (1765), 26/ 08/ 1765 y Códice 593 (1772-1773) 14/ 11/ 1773 y Códice 148 (1774-1775), 03/ 03/ 1774.
} 
Toda aquella región estaba envuelta en conflictos y disputas coloniales, y la región de frontera se convirtió en un lugar seguro para los cimarrones. ${ }^{7}$ En 1796, dos fragatas de guerra portuguesas vigilaban respectivamente Barra de Guayana y el río Oiapoque, en los propios límites, intentando refrenar tanto a los fugitivos como a los colonos franceses que se encontraban allí. Al año siguiente, navegando por el Cabo Norte, J osé de Santa Rita acabó llevando “cinco negros portugueses que habían huido de Cayena en un bote tan pequeño... [...] por espacio de 30 a 40 días hasta la punta de Mexiana donde fueron encontrados". La frontera era también un escondrijo social y económico. Los cimarrones habían desarrollado una microeconomía campesina y buscaban alianzas con otros sectores sociales. En 1765, se sospechaba de los fugitivos africanos de las obras de las fortificaciones de Amapá, pues "podemos presumir que se mantienen en los campos buscando en ellos las provisiones de maíz y plátanos". Aunque no era siempre así, los cimarrones acababan contando, en cierta medida, con el apoyo de los indios, los taberneros, los dueños de las canoas y otros esclavos (Baena, 1846, 54). ${ }^{8}$ Las alianzas y las solidaridades no tenían límites territoriales. Los cimarrones observaban las diferentes dimensiones de la frontera y veían a los colonos, los labradores y los desertores militares - franceses y portugueses- como socios eventuales para intercambios mercantiles, protección y alianzas. De esta forma, se puede entender por qué los cimarrones de las cataratas de Araguari llegaron a amenazar con "presentarse a los franceses “, intentando escapar de las persecuciones lusitanas. También en Araguari, en 1780, se temía que los fugitivos negros pasaran a la "población de Maroni que los franceses de Cayena han establecido intencionalmente" 9

Estas conexiones hicieron temblar a las autoridades coloniales; y las investigaciones revelarían algunos detalles. A través de un interrogatorio en Macapá, se descubrió en 1791 la forma en que los cimarrones se comunicaban en la frontera, manteniendo relaciones comerciales con los colonos franceses. Contaban con una base económica, hacían "salazones", teñían ropa, plantaban los campos, pastoreaban el ganado y fabricaban ladrillos para la construcción de las fortalezas francesas. Esto sin tener en cuenta la información de que los franceses habían enviado a un jesuita que era quien "gobernaba" a los cimarrones. Los refugiados ocupaban y buscaban autonomía y protección en diferentes áreas coloniales. Vivían del lado lusitano, pero comerciaban y trabajaban con los franceses del otro lado. Periódicamente cruzaban la selva y los ríos llevando provisiones para largas jornadas. El mismo juez de la Cámara de Macapá llegó a propo-

7 BNRJ , Códice I - 28, 27, 5 números 1-10, CÂMARA, J oão Pedro da. "Memória de alguns sucessos do Pará" 10/ 05/ 1776. APEP, Códice 172 (1777), 08/ 10/1777 y Códice (1780), 20/ 07/ 1780

8 APEPA, Códice 296 (1796), 27/02/ 1796 y Códice 614 (1795-1797), 27/ 04/ 1797 y 24/ 04/ 1797, Códice 702 (1797-1799), 08/05/ 1797; Códice 58 (1765), 19/ 02/ 1765 y Códice 71 (1766), 25/ 09/ 1766.

${ }^{9}$ APEPA, Códice 609 (1781-1788), 20/06/1780. 
ner que, en caso de que estos cimarrones fuesen capturados, se les soltase y se les entregase a sus señores. Sólo podrían salir de la cárcel para que "sus dueños los vendieran, lo cual deben hacer a diferentes países de donde nunca más vuelvan, de lo contrario, nos amenazará una ruina más grande, porque cada uno de estos esclavos es un piloto para aquellos continentes"10

Los cimarrones, los grupos indígenas y los desertores militares ocupaban las fronteras. Se decía que en las montañas del Unari había un "habitante francés por 150 negros". Dos años después, una petición de los concejales de la Cámara de la Villa de Macapá, admitía la existencia de la red de protección que los cimarrones tenían con los esclavos de las haciendas y los labradores "pues eran sus amigos parte del año, viniendo del mocambo donde se refugiaban a través de los campos de estas gentes, de dónde no sólo se llevaban los haberes que encontraban, sino también la ropa y las herramientas" (Baena, 1846, 54). ${ }^{11}$

\section{Encuentros y Mestizajes en las Fronteras de Surinam, Siglos XIX-XX}

En otra dirección en las fronteras de las Guayanas -- la Guyana holandesa, más tarde Surinam -- las regiones del Bajo Amazonas (Santarém, Óbidos, Monte Alegre, Alenquer y Curuá) también se establecieron formas campesinas - con la participación de los africanos y sus descendientes con los grupos indígenas -- en permanentes migraciones. De nuevo, los cimarrones con las poblaciones indígenas y otros aliados circunstanciales crearon -entre los ríos, muchas cataratas y escarpadas selvas- itinerarios, rutas y la cooperación para establecer escenarios transnacionales, redefiniendo los territorios y las fronteras étnicas.

Las comunidades de cimarrones - además de las antiguas - eran bien conocidas en la región del Bajo Amazonas. En 1805 las autoridades se referían a un "formidable mocambo de negros del río Curuá" desde 1799, "insultando a los habitantes de estos continentes con correrías continuas". Estos mocambos incluso habían sido atacados, de tal forma que "durante algún tiempo, estos continentes estuvieron tranquilos". No obstante, ya habían "nuevas fugas e insultos", y "no sólo de robos, sino de quemar casas y llevarse a mujeres libres". En 1811, el senado de la Cámara de Alenquer envió una petición clamando que se tomaran providencias, ya que incluso había rumores sobre una "invasión de los esclavos fugitivos" tantas eran las amenazas en que "continuamente viven los habitantes de esta villa". Los cimarrones estaban en "total estado de rebeldía y poco respeto" y los propietarios ni siquiera podían castigar a sus esclavos, "ya que si les

${ }^{10}$ APEPA, Códice 259 (1790-1794), Auto de preguntas 05/ 09/ 1791 y Códice 259 (1790-1794), 21/ 02/ 1793. ${ }^{11}$ APEPA, Códice 347, 21/ 02/ 1793 
aplicaban el más leve castigo, la amenaza de deserción los dejaba desamparados en sus tierras, tan sólo con sus mujeres e hijos". 12

Una expedición con casi 400 milicianos de Santarém, Alenquer, Óbidos y Monte Alegre partió en 1813. Los campamentos cimarrones fueron “arrasados” y "destruidos" y "todo se redujo a polvo y lo que era semilla fue lanzado al río", llevándose 75 capturados. La operación militar fue difícil, destacándose "trabajos infinitos que esta tropa había pasado para llegar a los lugares de los mocambos, pasando los arroyos con agua por la cintura, atravesando las sierras mas escarpadas, los caminos de pedregullos" y "por los parajes más difíciles". De hecho, todos estos "parajes" eran "entradas y salidas de los mocambistas" que conducían "canoas robadas", y eran considerados los "dueños de la selva”. Muchos esclavos mantenían siempre "más o menos trato con estos mocambistas". La expedición punitiva estuvo cerca de tres meses en la región, contando con el apoyo logístico de canoas, pólvora, guías, indios reducidos reclutados y provisiones. La destrucción de algunos campamentos no representaba necesariamente el fin de los cimarrones. Incluso con toda la movilización, a finales de 1813 ya se hablaba de un "nuevo mocambo" en la región de Curuá, formado "muy cerca del" destruido. Los años siguientes, los cimarrones siguieron apareciendo en las áreas de Óbidos y Alenquer. 1816 también fue un año marcado por el envío de nuevas expediciones punitivas. Aunque estaba situado en "medio de la selva, en un lugar muy extenso" y no en las orillas de los ríos, "antes de llegar al dicho mocambo presintieron [los fugitivos] la tropa". De todas formas, hubo un combate que dejó un saldo de 11 capturados y tres muertos. El destino de los que huían a esta región no era sólo los mocambos del Curuá. En 1818, Francisco J osé Pereira, establecido en el cultivo de cacao, en la villa de Santarém, reclamaba que sus esclavos fugitivos y los de otros habitantes estaban escapando hacia el Mato Grosso con la ayuda de "comerciantes de minas de Cuiabá". ${ }^{13}$ En las primeras décadas del siglo XIX, la región de Santarém y sus adyacencias continuarían siendo foco de cimarronaje. Las autoridades hacían referencia a un mocambo "renacido" en el Curuá, y en mayo de 1827 denunciaron un quilombo que "se dice está formado en el mismo poblado donde hace años fue destruido otro en el río Curuá". Un quilombo pequeño "compuesto por cinco casas" fue invadido el mismo año, sin embargo - admitieron las autoridades - no era el del Curuá, "pues éste está muy en el centro". Pero no siempre podía adentrarse totalmente en la selva - lo cual hacía fracasar la represión efectiva - puesto que "dichos quilombos siempre se forman en las cabeceras de los ríos y

\footnotetext{
12 APEPA, Códice 339, 08/ 10/ 1805; Códice 348, 24/ 11/ 1810 y 29/ 04/ 1811; Códice 343, 06/ 04/ 1811; Códice 347 (1780-1783), 02/ 01/ 1811.

13 APEPA, Códice 782, 24 e 28/ 04 e 07’05/ 1811, 27 y 31/ 10/ 1812, 11 y 25/ 02, 05/ 03 y 04/ 05/ 1813; Códice 663, (1813-1814), 16/ 05/ 1813; Códice 343, 22/ 08/ 1813; Códice 348, 23 y 25/ 04 y 20/ 05/ 1816.
} 
lagos, que en cierta estación del año son impenetrables”. Como medidas de prevención, intentaban controlar a los "regatones negros" que navegaban en Óbidos. Y se consideraban cimarrones todos los "negros que pasean de poblado en poblado, de casa en casa, sin que puedan demostrar que van a servicios de sus señores". ${ }^{14}$

Estos cimarrones mantenían contactos con los venteros, los taberneros, eventualmente con los regatones e incluso con los cautivos en los cultivos locales, puesto que estaban "mancomunados con los de la casa". Las expediciones contra los cimarrones del Curuá recomenzaron en la década del 40. La cuestión de las relaciones, los conflictos y la solidaridad entre los cimarrones y los indios en estos mocambos surgiría de nuevo. Se enviaron escoltas donde "se presumía que existía un quilombo en el río Trombetas de gente roja y negra”. ¿Quiénes serían? También las denuncias mencionaban "un mocambo arriba del río Trombetas y además del dicho mocambo, habían dos aldeas de indios bravos". En 1844 hubieron varios enfrentamientos, pues en julio se sospechó de la existencia de un mocambo en la localidad de Urubupaba; el mes siguiente una tropa marcharía para "golpear" un quilombo en los lugares llamados Ieningú e Ituqui. En esta ocasión, las fuerzas policiales contaron con la ayuda de los indios mundurucus, comandados por un "tuxáua". Después de algunos días de marcha a través de la selva, el cerco tuvo pocos resultados, ya que "un indio cómplice avisó a los negros" y escaparon, estando "bien prevenidos". En septiembre, otra tropa siguió hacia el río Mamiá y las autoridades descubrieron que había varios mocambos articulados, conjuntos de "casas" quemadas en tres áreas diferentes, alejadas entre sí de 1/2 a 4 horas. Los dos primeros mocambos tenían cinco "casas" cada uno y el último 16 "casas", con "muchos campos de yuca" y también, "cañaverales, bambusales y muchas otras plantaciones" (GOMES, 2001, p. 27-82)

Alonso y Funes encontraron varios indicios de conexiones - en las fronteras entre los cimarrones situados del lado de Brasil y las comunidades históricas del lado de Surinam (FUNES 1994; ALONSO, 1994). Contaban con el apoyo de los grupos indígenas locales y se registraron varias evidencias de contactos socio-económicos. En 1727, los misioneros franceses decían que los grupos indígenas - los Xarumas y los Parankari- de los ríos altos de la Guayana hacían comercio con los traficantes holandeses (MEIRELLES 1955 apud: FUNES 1994, 170). Los grupos indígenas - de ambos lados de esta frontera - migraban permanentemente, lo que les permitía mantener contactos con los cimarrones tanto en Brasil como en Surinam (ALONSO, 1994). Entre los indios, se destacaban los Tirió (llamados Tríos en la Guayana Holandesa), los Pianocotós y los

14 APEPA, Códice 808 (1825), 20/08/1825; Códice 840 (1826-1828), 03/ 01 y 14/ 05/ 1827 y Códice 851, 1ㅇ 07/ 1829. 
Xaruma. Desde 1749, los grupos indígenas instalados en la frontera establecieron contactos con los "negros del monte" de Surinam (FRIKEL 1971, p. 9) En 1875, Barbosa Rodrigues, un conocido viajero de la región del Trombetas señaló: “Los mocambistas, además de tratar con los blancos de las poblaciones, negocian por intermedio de los Arequenas con los Tunayanas, con los Charumas y Piana-ghotós, que a su vez negocian con los Trios y éstos con los mocambistas de Surinam" (BARBOSA RODRIGUES, 1875, p. 28-29).

Funes, en una entrevista hecha en 1992 a una de las últimas habitantes de uno de los quilombos del Bajo Amazonas - conocido como Pacoval - anotó el siguiente testimonio: "se encontraba tomando la orilla de la bahía, no lejos de la ciudad de Holanda, que ellos [los cimarrones] sabían donde era, pero no iban allá porque no se podía". En estas regiones del Amazonas -principalmente en los límites entre el Grão-Pará, Surinam y la Guayana Francesa - los grupos indígenas y los cimarrones reinventaron identidades y fronteras entre sí. En 1855, a raíz del envío de una expedición antimocambos se decía que en el río Mapuera había "indios, unos de color blanco y barbados y otros de color bronceado y barbados". Y que éstos estaban "en contacto con los negros quilombolas y que todos trafican con los comerciantes o los vendedores de Demerara, colonia holandesa" donde compraban armas de fuego y terciados (cuchillos) de "calidad superior como los que encontré en el mocambo" (FUNES, 1994, p. 172-173).

Otros relatos, ya entrado el siglo XX, confirman las evidencias de los contactos interétnicos y de la circulación en las fronteras, entre los cimarrones, las comunidades negras de Surinam, los grupos indígenas y los regatones. En las anotaciones de Derby, a finales del siglo XIX, aparecen informaciones que le dieron los últimos cimarrones. Le contaron que en una ocasión "una expedición subió por un afluente del Trombetas, rumbo al este, hasta donde pudieron llegar en canoas, y de allí atravesaron un extenso campo donde se encontraron con indios que negociaban con los blancos de la Guayana, recibieron de estos indios, tejidos, hachas, cuchillos, etc.” Negociaban arcos, flechas y perros ya que se decía que eran "muy hábiles enseñando a los perros a cazar sin estar acompañados". O sea, le compraban perros "a los negros para su propio uso o para volverlos a vender una vez adiestrados" (DERBY, 1897-1898, 370). En 1858, el jefe de Policía de Óbidos, Romualdo de Souza Paes de Andrade envió un oficio reservado al J efe de la Policía provincial de Pará. Había conseguido informaciones preciosas de Thomaz Antonio d'Aquino sobre el río Trombetas, donde "internándose por el río Arepecuruassú fue a dar con los indios que viven en las cabeceras del mismo río”. También revelaría que "encontró negros fugitivos, pues consta que los indios viven con éstos últimos”. El referido jefe de policía de Óbidos complementaría sus informaciones di- 
ciendo que "en el Trombetas existen por lo menos 300 esclavos porque ha sido un mocambo inexpugnable y con una existencia larguísima”. Finalmente alertaba:

\begin{abstract}
Nos cercan numerosos peligros, porque además del mocambo del Trombetas, y de otros más pequeños, que rodean este distrito, están los indios de este lado de la cordillera del Tumucumaque, y más allá de la misma cordillera hay tres repúblicas independientes de negros que infaliblemente deben comunicarse con los de acá por medio de los indios. V.S ${ }^{a}$ sabe que la parte más transitable de la cordillera supradicha es justamente la que nos sirve de límite con la Colonia Holandesa y que de esta ciudad [Óbidos] a la orilla de Surinam sólo hay 140 leguas de 18 grados, y en consecuencia es necesario que el gobierno le preste mucha atención al río Trombetas. Las repúblicas de las que le hablé más arriba a V.S ${ }^{a}$, reconocidas por los holandeses en 1809, están una al lado del alto Maroni, otra en el alto Saramaca, y otra en el alto Cotica, todas por consiguiente, a menos de 100 leguas de esta ciudad. Nuestros cultivos se debilitan por las fugas que diariamente sufrimos, y si no tomamos providencias, ciertamente dentro de poco estaremos sin un esclavo. ${ }^{15}$
\end{abstract}

Había grupos indígenas migrando y negociando, así como cimarrones formando comunidades transnacionales. En Surinam, desde el siglo XVII, los grupos de negros fugitivos atacaban las plantaciones y establecían sólidas comunidades, de las cuales muchas han llegado hasta nuestros días (PRICE, 1990, 1983). En 1760, una de las comunidades negras, llamada Aukaner (o Djuka), negoció la paz con las autoridades coloniales holandesas, que reconocieron su autonomía y le permitieron la ocupación de la tierra a cambio de que les devolvieran a los nuevos fugitivos y de lealtad. Estaban establecidos a lo largo del río Tapanahoni (cerca de la frontera con la Guayana Francesa) y llegó a tener 50 mil habitantes. Antes, en 1749, otro grupo de fugitivos africanos, situado entre los ríos Saramacca y Surinam, en el centro de Surinam, había intentado negociar la paz con las autoridades coloniales, la cual consiguieron en 1762. Denominados Saramaka, hoy cuenta con cerca de 50 mil individuos. Sin embargo, un pequeño grupo disidente de Saramaka siguió durante cinco años (1767) con las luchas anticoloniales, formando el grupo de los Matawai, que actualmente cuenta con unos 4.000 mil individuos. Parte de la lengua criolla de los Saramaka -- una invención lingüística - está enraizada en el portugués, porque los esclavos fugitivos que formaron estas comunidades, en los siglos XVII y XVIII, pertenecían a judíos sefarditas (y sus descendientes) que llegaron a Surinam, en compañía de los holandeses, después de haber sido expulsados del Noreste brasileño en el siglo XVII. Nuevos grupos de negros fugitivos surgieron a finales del siglo XVIII, entre los cuales se destacan los Aluku (también llamados Boni). Éstos pasaron la frontera con la Guayana Francesa en 1776 y a diferencia de

${ }^{15}$ APEPA, Documentación en Cajas (1858), 09/ 02/ 1858. 
otros grupos, sólo lograron establecer tratados de paz en 1860, no con los holandeses, sino con los franceses. Su población actual está de cerca de las 6 mil personas y casi todos viven en la Guayana Francesa. Con tratados de paz y negociaciones, estos grupos desarrollaron sus culturas y generaron micro-sociedades dentro de la selva, a lo largo de los siglos XIX y XX, sin quedarse aislados (PRICE 1990, 1983).

Con estas comunidades negras de Surinam, los indígenas y probablemente los cimarrones, mantuvieron conexiones que llegaron hasta las fronteras de las Guayanas y las borraron, implicando también a los fugitivos de las propiedades lusitanas, holandesas, españolas y francesas. A finales del siglo XIX, el barón de Marajó afirmaba que los "indios y los negros del mocambo se comunicaban con las aldeas de negros que poblaban las cabeceras del Saramaca y del Surinam en la colonia holandesa “. Tavares Bastos comentaba que los cimarrones "intercambiaban con los holandeses de la Guayana sus productos”. En una expedición en 1928 a la región de Óbidos y Tumucumaque, Cruls observó que todavía existían cimarrones. Allí, ya hacía algún tiempo que comerciaban la castaña, el cumarú (un tipo de fragancia) y el aceite de copaiba. Durante el viaje supe que estos últimos cimarrones tuvieron contacto con los grupos indígenas Ariquena, Xaruma y Tunaiana. Contactos rodeados de conflictos, porque robaron mujeres indígenas y fueron atacados, yendo a establecerse en otros puntos más bajos del río. Aún así, a través de los grupos Tirió y de los Pianocotós en la frontera, estos cimarrones establecieron incluso contactos con los "negros del monte (bush negroes)" de Surinam. Investigando a los indios Tirió en las fronteras, Protássio Frikel destacó que "anualmente los Djuhas [Djuka, comunidad negra] hacían viajes comerciales a las aldeas Tirió [...] los principales artículos de intercambios mutuos eran perros de caza y arcos fuertes por el lado indio, y tela roja, abalorios e instrumentos de hierro por parte de los negros" (MARAJÓ, 1895; SALLES, 1971; CRULS, 1945; FRIKEL, 1955). Fray Alberto Krause, cruzando la cordillera del Tumucumaque en 1944 recogió en un testimonio del cacique Aparai de los Macuru, la información de que en aquella región habían "18 tribus de indios y 4 de negros “. Según Krause estas "tribus negras se componen probablemente de negros fugitivos, los Meico're, una de estas tribus habla el dialecto carába”. Funes -basándose en Protássio Frikel -- señala que Meico're era igual a mekoro o boschnegers (KRAUSE, 1945; FRIKEL, 1971 apud FUNES, 1994).

En lo que se refiere al norte amazónico y sus fronteras transnacionales tenemos que reflexionar - al hablar de "mezclas" - quiénes eran "indios" o "negros" y donde se parecen en las narrativas coloniales y postcoloniales. Podemos pensar en la constitución de grupos étnicos, sus percepciones y expectativas en torno a los contactos, el te- 
rritorio, el ecosistema y las cosmologías reinventadas. ${ }^{16}$ En las regiones del extremo norte amazónico, por ejemplo, las micro sociedades indígenas sugieren eso a partir de su etnohistoria y cosmologías. Podemos destacar, en especial, a los Waiwái (Roraima y Pará), los Waiãpi, los Kali 'em, los Wayana-Aparai y los Tirió (Pará), además de los Galibi, los Palikur (Amapá) e incluso los Karifuna, un grupo que surgió en Amapá de las experiencias de los contactos interétnicos en los siglos XVII y XVIII. Los Waiãpi, que actualmente cuentan con un área demarcada en Amapá, registran en sus narrativas orales las disputas entre los franceses y los portugueses, la construcción de fortalezas militares y las alianzas y los conflictos consiguientes. En sus memorias, se refieren a los grupos de negros con los que entraron en contacto y los llaman Tapajon, posiblemente descendientes de fugitivos africanos (GALLOIS, 1994).

En la región del actual estado de Roraima, las investigaciones antropológicas indicaron cómo los indios de Waiwái de la aldea de Kaxmi continuaban comercializando productos que llegaban a otras aldeas Waiwái y los repasaban - en buena parte -- a los indios Tirió, que migraban constantemente. Y estos productos también llegaban a los cimarrones de los grupos ("negros del monte") de Surinam. Además de perros y papagayos, los Waiwái comercializaban ovillos de algodón hilados a mano, bija, aceites, resinas y otros productos. A cambio obtenían ollas de aluminio, cuchillos, hachas, otras herramientas de hierro, mosquiteros y abalorios (HOWARD, 1993, p. 235-236). Las redes de intercambio y otros contactos de los Tirió - que llegaban hasta los maroons y ciudades costeras de Surinam - existieron durante más de dos siglos. Antes, incluían a los traficantes de indios, a las patrullas de soldados coloniales, a los regatones (barcos de comercio que recorren los ríos de la región amazónica), a los desertores y a los fugitivos. Actualmente, los intercambios se hacen con las misiones religiosas, los comerciantes de arte indígena, los buscadores de oro y las agencias gubernamentales o no.

\section{Consideraciones Finales}

En áreas de fronteras, podemos pensar procesos de etnogénesis a través de la formación de comunidades de fugitivos y de los trabajadores - africanos e indígenas de varias procedencias étnicas - de las reducciones, haciendas y misiones. La migración constante, además de los desplazamientos coloniales de miles de trabajadores hacia unidades productivas, generaron movimientos transétnicos que aún necesitamos conocer (OLIVEIRA, 1999a, 1999b), puesto que se producen simbologías, mitologías y cultura material que permanecen aún ocultas en trabajos de etnología y etnohistoria.

16 Ver varios estudios en Albert e Ramos (2002). 
Cuando comencé a realizar la presente investigación (en archivos coloniales de Brasil y de la Guayana Francesa), el hecho que más me llamaba la atención era - más allá de las fuentes archivísticas abundantes - la rica bibliografía - equivocadamente llamada historia regional - totalmente desconocida. Una complejidad apuntada por numerosos autores y también cronistas de la época, reforzada por las innumerables peticiones y correspondencias coloniales. Considerando esa complejidad, me he visto tentado de encontrar categorías, imágenes y metáforas que puedan representar aquellos escenarios y experiencias. Frente al cuadro de disputa colonial y a la lógica avasalladora que invade (y confunde) la naturaleza de la documentación colonial, pensé en la imagen del "tablero de ajedrez", en una perspectiva de avances y retrocesos de las numerosas instancias coloniales en la región amazónica: franceses, portugueses, ingleses, españoles y holandeses. La idea del "tablero de ajedrez" con sus piezas, sentidos de avance y posicionamientos estratégicos de retrocesos, etc., parecía perfecta. Pero luego percibí que esa imagen - transformada en metáfora - podría ser una trampa, y con ella no conseguiría avanzar en una crítica historiográfica. Tablero de ajedrez, piezas, jugadores y estrategias insinuaban una lógica de racionalidad. Exactamente lo que no había en estas regiones de fronteras, donde el conflicto entre dominio y poder colonial nunca existió efectivamente. Allí no había certezas de poblamiento o astucias de ocupación. Observé entonces que la mejor imagen y/ o metáfora era la de "Alicia en el País de las Maravillas". Ante cada avance: un retroceso. Ante cada certeza: la improvisación. Para cada riesgo: un provisional.

\section{Referencias}

ALBERT, B.; RAMOS, A. R. (Org.). Pacificando o branco - Cosmologias do contato norte-amazônico. São Paulo: Ed. Unesp, 2002.

ALONSO, J osé Luís Ruiz-Peinado. Hijos del río - Negros del Trombetas. En: GARCIA, J ordán Pilar; IZAR, Miguel; LAVINA, J avier (Comp.). Memoria, creación e historia. luchar contra el olvido. Barcelona. 1994. p.349-357.

ALONSO, J osé Luís Ruiz-Peinado. Publicadores de la Amazonia. Cimarrones del Trombetas. África Latina Cuadernos, Barcelona, n. 21, p. 59-68, 1994.

BAENA, A. L. Monteiro. Discurso ou memória sobre a instrução dos franceses de caiena nas terras de Cabo Norte em 1836. Maranhão, 1846.

BARBOSA RODRIGUES, J oão. Rio Trombetas. En: EXPLORAÇÃO e estudo do Vale do Amazonas. Rio de J aneiro: Typografia Nacional, 1875.

CRULS, Gastão. A Amazônia que eu vi: Óbidos - Tumucumaque. São Paulo: Ed. Nacional, 1945.

DERBY, Oliver A. O Rio Trombetas. Boletim MPEG II, Fasc. 1-4, 1897-1898. 
FRIKEL, Protássio. Dez anos de aculturação Tiriyó: mudanças e problemas (19601970). Boletim MPEG, publicaciones sueltas, n.16, 1971.

FRIKEL, Protássio. Tradições Histórico-Lendárias dos Kacúyana e Kahyana. Revista Brasileira do Museu Paulista, São Paulo, v. 9, 1955.

FUNES, Eurípedes. Nasci nas matas, nunca tive Senhor: história e memória dos mocambos do Baixo Amazonas. 1994. Tesis (Doctorado en Historia) - Universidad de São Paulo.

GALLOIS, Dominique Tilkin. Mairi revisitada: a reintegração da fortaleza de Macapá na tradição oral do Waiãpi. São Paulo: Núcleo de História Indígena e do Indigenismo, USP, FAPESP. 1994.

GOMES, Flávio dos Santos. Amostras Humanas: índios, negros e relações interétnicas

no Brasil Colonial. En: BARCELLOS, Claúdia; MAGGIE, Yvonne (Comp.). Raça como retórica: a construção da diferença. Rio de Janeiro: Civilização Brasileira, 2001. p. 27-82.

. Los cimarrones y las mezclas étnicas en las fronteras de las Guayanas. Siglos $\bar{X} \bar{V} \bar{I}-\bar{X} \bar{X}$. Procesos de Historia. Revista Semestral de Historia y Ciencias Sociales, Venezuela, v. 16, p. 24-39, 2009.

HOWARD, Catherine V. PAWANA: a farsa dos 'visitantes' entre Waiwai da Amazônia setentrional. In: CASTRO, Eduardo Viveiros de; CUNHA, Manuela Carneiro da. (Comp.). Etnologia e história indígena. São Paulo: NHII/ USP, FAPESP. 1993. p. 235136.

KRAUSE, Frei Alberto. Viagem ao Maicuru: Revista Santo Antônio, n. 1, 1945.

MARAJ Ó, J osé Coelho da Gama, Barão de. As regiões amazônicas: estudos coreográficos dos Estado do Grão Pará e Amazonas. Lisboa: Impr. de L. da Silva, 1895.

MEIRELLES, Frei Bonifácio. Como Frei Francisco de São Marcos descobriu o Trombetas. Revista de Santo Antônio, 1955.

OLIVEIRA, J oão Pacheco de. (Org.). A viagem da volta: etniidade, política e reelaboração cultural no nordeste indígena. Rio de J aneiro: Contra Capa Livraria, 1999a.

OLIVEIRA, J oão Pacheco de. A Problemática dos Índios Misturados e os Limites dos Estudos Americanistas: um Encontro entre Antropologia e História. Ensaios em Antropologia Histórica, Rio de Janeiro,p. 99-123, 1999b.

PRICE, Richard. Alabi's world. Baltimore: The J ohns Hopkins University Press, 1990. First-time: the historical vision of Afro-American people. Baltimore: The Johns Hopkins University Press, 1983

SALLES, Vicente. O Negro no Pará, sob o regime da escravidão. Belém: FGV, 1971. 